\title{
PERSPECTIVAS PARA A EdUCAÇÃo física esCOLAR
}

\author{
João Batista Freire da SILVA*
}

Queria aproveitar o palestrante que me precedeu, o Prof. Go Tani, para dizer que eu também, neste início de fala, estou nervoso. Todas as vezes que me coloco à frente das pessoas para lhes dizer alguma coisa, demoro algum tempo até reequilibrar as emoções. Julgo que isso é muito positivo, é um testemunho de nossa humanidade, especialmente a quem participa desse universo tão sensível da Educação Física. De que falamos na Educação Física? De ossos, de músculos, de sangue, de atividade corporal. E diferente de falar em uma mesa de História ou de Filosofia, com todo o respeito que temos que ter por essas áreas.

Prossigo citando Gregory Bateson, esse admirável pensador contemporâneo: ...a verdade significaria uma correspondência precisa entre a nossa descrição e aquilo que descrevemos, ou entre o nosso entrecruzamento total de abstraçōes e deduçōes e uma compreensão absoluta do mundo exterior" (1987, p.33). A verdade, tomada nesse sentido, não é atingivel. E mesmo ignorando as barreiras de qualquer código, $o$ fato de a nossa descrição ser em palavras, nümeros ou em imagens, enquanto o que descrevemos é carne, sangue e ação - mesmo ignorando essa barreira da tradução, nunca seremos capazes de reivindicar um conhecimento final de seja o que for $(1987$, p.33).

Se o que Bateson fala tem sentido, e tudo indica que sim, nós, da Educação Física, temos um problema muito grave para resolver. E muito difficil para qualquer teórico, tendo que se expressar por palavras, descrever a ação corporal, pois esta $€$ uma sintese de representações mentais, de emoções, de sangue, nervos, etc. Como descrever tudo isso? $E$ tarefa das mais complicadas nos propormos falar, descrever, teorizar, especificamente sobre a ação corporal. Esse, provavelmente, é um dos motivos por que fazemos tanta confusão térica. $€$, talvez, o que gera tantas dificuldades para especificar um objeto de estudo ou identificar um campo de atuação profissional.

Quando falamos de Educação Física, falamos de coisas sensíveis, de coisas sintéticas. A ação corporal não discrimina entre o que é psicológico, o que é social, o que é moral ou o que é cognitivo. Quando andamos, não andamos psicologicamente; não corremos socialmente; não saltamos cognitivamente. Saltamos, corremos, andamos, apenas isto. $O$ que é extremamente dificil de compreender. $O$ discurso sobre tais ações, para bem traduzf-las, seria de tal ordem de complexidade e sutileza que ainda não aprendemos a elaborá-lo.

Hoje, no Brasil, fazemos muito mais História da Educação Física (ou História na Educação Física), Filosofia da Educação Física (ou Filosofia na Educação Física), que Educação Física. Acho isto perfeitamente compreensível, já que, em nosso país, passamos muitos anos praticando uma verdadeira orgia de práticas.

Passamos décadas fazendo, e fazendo, sem quase nada de reflexão. De uns tempos para cá, entramos na era da reflexão, na hora de pensar nossa prática, de escrever sobre ela, e não será tão cedo que sairemos disso. Até porque, na nossa sociedade conservadora, nos acomodamos rapidamente a todas as coisas. A crise da Educação Física está rendendo, mas na próxima década vamos nos esvaziar e não teremos muito mais sobre o que falar se continuarmos a não transformar os discursos em práticas. Como se não bastasse o descaso típico dos nossos governantes com a educação, ainda temos que agüentar esse palavrório interminável, que cada vez se distingue melhor daquilo que realmente pode ter alguma

*Faculdade de Educação Física da Universidade Estadual de Campinas. 
conseqüência positiva.

A Educação Física melhorou muito nos últimos anos; vê-se isso por todo o Brasil. Mas as perspectivas ainda são sombrias. Mesmo que nossa formação profissional fosse muito boa, que, por um milagre, as Faculdades de Educação Física começassem a oferecer um bom ensino, ainda assim a Educação Física no Brasil continuaria mal por muito tempo. As escolas estão caindo aos pedaços, os salários dos professores são péssimos. Ou seja, mesmo com um bom conhecimento, as condiçōes de trabalho sendo precárias, $\epsilon$ difícil ter motivação para produzir com qualidade. Não se pode, por mais que se teorize, imaginar que alguém vai começar a ser bom professor vivendo a situação que os professores vivem. Apesar disso, os bons trabalhos tornam-se mais freqüentes. São professores que devem ter fortes motivações interiores, o que lhes permitem ultrapassar os obstáculos.

$O$ que estamos fazendo hoje é tentar recuperar um pouco do tempo perdido e pensar naquilo que nos toca mais de perto, ou seja, a formação do nosso profissional, para que, no futuro, tenhamos um profissional melhor. Fazemos isto, apesar das circunstâncias que já descrevi, que não melhorarão senão por uma intensa luta também no terreno político.

Se tudo o que falarmos e fizermos no nosso campo de atuação profissional, não resultar em mudanças no comportamento corporal das pessoas, para melhor, não terá qualquer valor. Acho interessantíssimo estarmos em uma universidade, pesquisar, escrever, mas isso tudo tem que resultar em mudanças de comportamento social. No nosso caso, mais especificamente de comportamento corporal. As pessoas têm que, corporalmente, sofrer alguma mudança graças ao nosso estudo, graças ao nosso trabalho, senão, não adianta nada. Portanto, o que estamos fazendo é tentar modificar, de alguma forma, as nossas práticas. Esperamos que a Educação Física veicule pedagogicamente nossas idéias, nossas pesquisas, e que possa, de alguma maneira, transformar tudo isso em boas práticas.

Nossa atuação tem sido mais freqüente na escola que em outras áreas. Portanto, não dá para criticar a Educação Física sem fazer uma crítica, mesmo que rápida, à escola. A escola sucateada atinge mais fortemente o professor de Educação Fisica que os outros professores, porque os outros têm uma sala, um local de trabalho, e o professor de Educação Fisica não. Isso é indigno. Năo é justo que um profissional seja submetido a tais condições. Não é à toa que nada na escola dá certo.

Procurem lembrar de compromissos pedagógicos que tenham sido bem cumpridos. E muito raro encontrar algum. Sistematicamente, a escola, no sentido em que queremos ver a educação, é um fracasso. Não sei se ela tem sido um fracasso em um outro sentido, por exemplo, no de fazer com que as pessoas aprendam, não os conteúdos explícitos, mas a se comportarem de uma determinada maneira. As pessoas não aprendem Matemática, Português ou Ciências; mas aprendem a sentar, não se mexer, não criticar, etc. Nisso parece que a educação tem tido muito êxito.

Quanto aos motivos do fracasso escolar, no que diz, respeito aos conteúdos explícitos, considerando o que foi mencionado anteriormente, pergunto: como pode uma criança que vem de sete anos de atividade corporal e de fantasias, no mínimo razoável, ficar presa em uma cadeia durante quatro horas? Somente isto já constituiria motivo de notável fracasso escolar.

Tanto na sala de aula quanto na Educação Física, temos que trabalhar com a criança real, pelo menos aproximadamente com aquilo que ela $\epsilon$, e não com a criança ideal, com um modelo. Preparamonos para educar a criança boazinha, comportada, silenciosa, cooperativa. Mas existe uma outra criança, agressiva, egoísta, malcomportada, competitiva, que não podemos educar porque não a enxergamos. Por exemplo, a Educação Física resolve que não vai trabalhar com a competição. Agora, se a criança for competitiva, $\epsilon$ evidente que esse seu aspecto não será educado. Ficamos somente com um lado da criança. Teimamos em educar somente uma parte da criança. Na sala de aula só se procura educar a criança que fica sentada. Até parece que o órgão cognitivo principal da criança é a bunda. Criança em pé, criança que corre, não pode ser educada. Onde estão as teses de mestrado e doutorado que mostram que se aprende melhor sentado? Nunca um educador se atreveu a escrever algo dizendo isso. Acredito que não é por acaso que ninguém aprende nada na escola.

Portanto, teriamos que assumir que devemos educar a criança real, e nós não estamos preparados para isso. Nas faculdades não se ensina a lidar com a criança real. Como é que a gente lida com a criança 
agressiva, com uma criança perversa, infeliz, egoista, bagunceira? Fomos ensinados a trabalhar com a criança quieta, boazinha. Chegamos na escola e não encontramos essa criança; então, não conseguimos educar.

A escola se propõe educar a personalidade da criança, só que a "persona" da escola não tem corpo. Para nós da Educação Física, não é muito estranho pensar em uma "persona" com corpo. Porém, para a escola, a educação da personalidade não é educação corporal, porque se está educando uma personalidade estratosférica, fluída, que está pairando no ar, em algum lugar que não sabemos onde. $O$ espirito, a mente, a personalidade, a alma, são entidades que nunca ninguém me mostrou. Ouero ver aqui no planeta Terra estas entidades que na escola não vejo. S6́ vejo corpo, sangue, músculos e ossos. Como não aprendi a educar a ação corporal, não educo, porque fui habituado a aceitar que existem entidades que nunca vi, mas estão nas palavras, no papel. Então, educação da personalidade não é a educação de uma criança real, de alguém que materialmente existe. Não assumimos a matéria, não assumimos o corpo como entidade material, representativa de nossa realidade existencial.

Imagino que, se o sistema escolar fosse honesto, digno, se proporia a receber a criança aos sete ou oito anos do jeito que a criança fosse. Quando ela chega à escola, vem sabendo muita coisa sobre Matemática, sobre Português, sobre Física. Porém, ela formou esse conhecimento para si mesma, para seus problemas particulares, circunscritos ao seu mundo pequeno. Ela está se formando como o indivíduo que será pelo resto da vida; tem um conhecimento que lhe serve muito bem individualmente, mas que the serve ainda muito pouco socialmente. Então, o que a gente vê, é a escola pegando uma criança que tem uma linguagem matemática muito individual e lhe ensinando uma linguagem matemática social, para que ela possa dar uma utilidade social ao seu conhecimento. Em relação às línguas, a mesma coisa. Eu pergunto: será que, em relação à Educação Física, não ocorre o mesmo?

Sempre vi crianças chegando à escola com muito conhecimento em atividades corporais. A criança brinca e brinca muito bem, muito melhor que nós. Mas vejo que ela tem um conhecimento muito particular, que lhe serve individualmente, mas muito pouco socialmente. Basta ver um jogo sem regras. Ela ainda não sabe o que fazer quando alguém não lhe coloca regras, porque seus movimentos corporais ainda não conseguem interagir com um grupo social um pouco mais complexo. Sendo assim, ela terá que aprender a dar uma utilidade social a essa sua motricidade ainda bastante individual.

Em termos de perspectivas, suponho que nós poderíamos também alfabetizar as pessoas corporalmente; poderíamos conseguir que as crianças aprendessem a dar um bom uso social ao seu conhecimento corporal. Ou seja, não podemos sair por aí chutando de qualquer jeito, pulando de qualquer jeito, correndo de qualquer jeito. A criança terá que aprender a exercer sua motricidade no grupo social. E terá que aprender a fazer isso conosco. Mas, como faremos para ensinar isso? Entendo que a tarefa da escola é integrar a criança ao grupo social, adaptar e formar um conhecimento que se ajuste a relações sociais complexas, não no sentido de moldar a criança à sociedade tal como ela está al. Não gosto da sociedade como está. não quero que meus alunos se conformem com o que está aí; quero que eles entendam e transformem o mundo. Portanto, precisamos de crianças muito inteligentes.

Nos assustamos quando vemos a Educação Ftsica lidar com dificuldades ainda maiores que as das outras disciplinas. Por que somos tão discriminados, tão diferentes? Acontece que lidamos com o corpo, representamos o corpo na escola, e todo mundo tem medo do corpo. Sabemos que o corpo perece, vai se acabar; o corpo é mortal. Isto é uma tradição da nossa formação intelectual, da formação do pensamento humano. Ouem representa o corpo na escola, seguramente continuará discriminado pelos que representam o intelecto, a mente, a imortalidade. Nós, da Educação Física, não poderíamos ter uma Academia de Imortais. Somos os únicos seres mortais da escola, os que apodrecerão quando morrerem. Parece que não há um céu para nós.

\section{REFERENCIA BIBLIOGRÁFICA}

BATESON, G. Natureza e Espirito. Lisboa. Dom Quixote, 1987.

Rev. paul. Educ. Fts., São Paulo, 5(1/2):76-78 jan./dez.1991. 